\title{
Proposta de avaliação de pessoas com deficiência na escola: reflexões acerca das múltiplas linguagens
}

\section{Proposal for evaluation of people with disabilities at school: reflections on multiple languages}

\author{
José Anchieta de Oliveira Bentes* \\ Rita de Nazareth Souza Bentes* \\ Huber Kline Guedes Lobato ${ }^{* * *}$
}

\section{Resumo}

O objetivo principal deste trabalho é apresentar os resultados do uso de uma proposta de avaliação que considere as capacidades e potencialidades de pessoas com deficiência na escola. A pesquisa foi construída no ano de 2017, a partir da avaliação de quatro pessoas com deficiência na escola, sendo: com paralisia cerebral (PC), denominado Léo; com múltipla deficiência sensorial-visual (MDVI), denominado Alex; com deficiência intelectual (DI) - síndrome de Down, denominada Ana; com surdez (S), denominada Lia. As quatro pessoas são estudantes de uma escola da rede municipal pública de Belém, Pará. O problema de pesquisa é: como avaliar pessoas com deficiência na escola considerando as múltiplas linguagens? A análise dos dados revelou que a avaliação e as ações de múltiplas linguagens podem ser bastante úteis para a elaboração do currículo e para o programa individual de pessoas com deficiência na escola e em sala de aula, superando a pedagogia da alfabetização tradicional e conservadora, que considera apenas a escrita alfabética no cotidiano escolar.

Palavras-chave: Avaliação da deficiência. Ensino e aprendizagem. Múltiplas linguagens. Pessoas com deficiência.

\section{Abstract}

\begin{abstract}
The main goal of this work is presenting the results of the use of an evaluation proposal tool that takes into account the capacities and potentialities of people with disabilities at school. The research was conducted in 2017 and four people were evaluated: Léo, a student with cerebral palsy (CP); Alex, a student with multi-sensory impairment (MSI); Ana, a student with Down Syndrome (DS); Lia, a deaf student. All of them are students at a municipal school in Belém, Pará, Brazil. The research problem is the following: How can we evaluate students considering multiple languages? The data analysis reaveled that the evaluation and and multiple language actions can be useful for the curriculum elaboration and for the individual program of people with disabilities in school and in classroom, overcoming the traditional literacy pedagogy that considers only the alphabetial writing in school daily life.
\end{abstract}

Keywords: Evaluation of disability. Teaching and learning. Multiple languages. People with disabilities.

\author{
Recebido em 06/08/2018 - Aprovado em 31/01/2019 \\ http://dx.doi.org/10.5335/rep.v26i2.8468
}

Pós-doutor em Educação pela Pontifícia Universidade Católica do Rio de Janeiro. Doutor em Educação Especial pela Universidade Federal de São Carlos. Professor adjunto da Universidade do Estado do Pará, Brasil. E-mail: anchieta2005@yahoo.com.br

** Doutoranda no Programa de Pós-Graduação de Filologia e Língua Portuguesa (Faculdade de Filosofia, Letras e Ciências Humanas - Universidade de São Paulo / Doutorado Interinstitucional - Universidade Estadual do Pará). Professora do Curso de Letras-Libras do Departamento de Língua e Literatura da Universidade Estadual do Pará, Brasil. E-mail: ritasbentes@yahoo.com.br

*** Mestre em Educação pela Universidade do Estado do Pará. Professor do Magistério Superior do Instituto de Letras e Comunicação da Universidade Federal do Pará. Professor de Língua Brasileira de Sinais - Sexto Prolibras. Tradutor/ Intérprete da Língua Brasileira de Sinais - Prolibras 2010, Brasil. E-mail: huberkline@gmail.com 


\section{Introdução}

As práticas de avaliação tradicionais no universo educacional estiveram e estão presas a testes psicométricos que, muitas vezes, limitam o processo avaliativo ao uso de procedimentos estatísticos, para verificar a aprendizagem e o desempenho dos alunos na escola. A avaliação tradicional, focada em padrões estabelecidos e em médias aritméticas, desconsidera outras aprendizagens na escola e, inclusive, rejeita as múltiplas linguagens de seus aprendizes.

A reflexão sobre o trabalho com as múltiplas linguagens no âmbito educacional e no universo de pessoas com deficiências na escola é o foco deste estudo. Essa temática é relevante e atual, pois considera as características subjetivas de comunicação, propondo ser formativa, reconhecendo as capacidades e desenvolvendo potencialidades, as quais poderão facilitar o processo de ensino e aprendizagem. A discussão sobre o trabalho com múltiplas linguagens remete a temáticas inerentes à avaliação de pessoas com deficiência no contexto escolar. Por isso, torna-se interessante responder: o que é avaliar?

Para Quadros e Cruz (2011, p. 43), “[...] realizar uma avaliação da linguagem é fundamental para identificar o que está adequado e o que necessita ser adquirido e, posteriormente, possibilitar uma adequada intervenção".

A avaliação precisa perpassar pela perspectiva das múltiplas linguagens que incluem os desenhos, a escrita, a música, a dança, a pintura, entre outras - enquanto uma forma de complementação do conhecimento que as pessoas com deficiência possuem, e não como uma forma de medir o que se apreendeu nas disciplinas. A avaliação é:

Uma tarefa complexa que não se resume a realização de provas e atribuição de notas. A mensuração apenas proporciona dados que devem ser submetidos a uma apreciação qualitativa. A avaliação, assim, cumpre funções pedagógico-didáticas, de diagnóstico e de controle em relação as quais se recorrem a instrumentos de verificação do rendimento escolar (LIBÂNEO, 1994, p. 195).

Com isso, compreendemos que a avaliação é um processo permanente do trabalho do professor, na intenção de perceber se seu alunado aprendeu ou não. A avaliação reverbera diretamente na qualidade do trabalho docente e proporciona mudanças na realidade escolar. A avaliação:

É um processo pelo qual se procura identificar, aferir, investigar e analisar as modificações do comportamento e rendimento do aluno, do educador, do sistema, confirmando se a construção do conhecimento se processou, seja este teórico (mental) ou prático (SANT'ANNA, 1995, p. 29-30). 
A avaliação precisa servir para informar aos professores as capacidades e potencialidades das pessoas com deficiência, as múltiplas formas como estas pessoas resolvem determinados problemas de aprendizagem e quais são os recursos que refletem de forma qualitativa em seu aprendizado. Isso permitirá a elaboração de estratégias de ensino adequadas para cada pessoa.

Assim, neste artigo, apresentamos a perspectiva das múltiplas linguagens para impulsionar mudanças no modo de ensinar as pessoas com deficiência na escola. ${ }^{1} \mathrm{O}$ principal argumento para esta empreitada é que existe, na sociedade atual, uma multiplicidade de formas de linguagens e de culturas.

A perspectiva que assumimos é a das múltiplas linguagens, pretendendo superar as abordagens de alfabetização tradicionais e conservadoras, que consideram apenas a escrita alfabética. Sustentamos a ideia de que é preciso considerar a variedade linguística, a variedade cultural e as diferenças dos alunos, de seus corpos, de suas capacidades sensoriais, de seus interesses individuais e coletivos e de suas potencialidades para o desenvolvimento do trabalho do professor.

O objetivo maior do professor, com esse trabalho, é promover a alfabetização pelo letramento. Dessa forma, pode haver a participação de todos os alunos, garantindo que todos aprendam, todos participem do trabalho em sala de aula, todos interajam ao seu modo com os demais e, com isso, possam efetivamente se sentir incluídos e valorizados em sala de aula.

A alfabetização a partir da perspectiva do letramento assume uma nova configuração, ultrapassando mitos e princípios ideológicos incrustados na escola, fundamentados na normalização dos corpos e na exclusão de crianças, adolescentes e jovens que não atendem aos requisitos do padrão estabelecido de corpo normal, pois Ropoli et al. (2010, p. 6) versam que "[...] cada aluno tem a possibilidade de aprender, a partir de suas aptidões e capacidades".

Para que ocorra essa possibilidade de aprender, ampliamos o uso do texto impresso ou escrito, para o uso de textos semióticos, considerando a identidade de pessoas com deficiência, com quem trabalhamos. A expressão e a recepção destas pessoas podem ser realizadas por diversas formas: pela visão, pelos gestos, pelos sinais, pelos desenhos ou gravuras, pelo movimento do corpo, etc. Rompemos com a pedagogia da alfabetização centrada no monolinguismo, na escrita baseada em regras normativas, no monoculturalismo e na normalização dos indivíduos.

Para contextualizar essa discussão sobre múltiplas linguagens, citamos o exemplo do livro digital, que possibilita, por meio de programas próprios, ampliar a fonte em que o livro é editado: 
O livro em formato digital em texto favorece a comunicação de seu conteúdo para leitores com diferentes características e habilidades. Pode ser lido no computador e em dispositivos especializados, transformação em áudio impresso à tinta, com fonte em tamanhos variados, em Braille. Além disso, pode ser veiculado em diferentes suportes de armazenamento como CDs, DVDs, pendrive, em servidores web para acesso via Internet, etc. (MELO; PUPO, 2010, p. 7).

O livro digital une diversas modalidades de linguagem: a visual, a escrita alfabética, a digital, a auditiva. Por meio do livro digital, pessoas com deficiência visual, bem como aquelas que apresentam comprometimentos físicos que limitam seus movimentos, podem se apropriar ou manipular a informação impressa ou as informações textuais.

Neste artigo, vamos incluir alguns discursos a respeito da ampliação dos termos alfabetização - entendido como aquisição do sistema de escrita alfabética - e letramento - entendido como uso e aplicabilidade dos textos escritos -, alcançando as diversas manifestações de linguagem e estabelecendo relações com o ensino e a aprendizagem de pessoas com deficiência.

O objetivo, portanto, é apresentar os resultados do uso de uma proposta de avaliação que considere as capacidades e potencialidades de pessoas com deficiência na escola. A partir disso, pretende-se obter, ao final da pesquisa, uma ferramenta sugestiva para avaliação das habilidades - as quais denominamos de múltiplas linguagens - dessas pessoas.

O artigo faz referência à avaliação das pessoas com deficiência na escola, destacando a relevância de obter estratégias e subsídios para apoiar os profissionais que atuam nesse contexto. A questão central da pesquisa é: como avaliar pessoas com deficiência considerando as múltiplas linguagens?

\section{As múltiplas linguagens}

A discussão pode ser encapsulada na expressão múltiplas linguagens, que é capaz de abarcar os fundamentos de uma cultura local, algumas vezes marginalizada, com outras culturas institucionalizadas e globalizadas, com uma multiplicidade de formas de comunicação, de linguagens e de canais de mídia.

Nos termos que:

Vivemos em um mundo multissemiótico para além da letra, ou seja, um mundo de cores, sons, imagens e design que constroem significados em textos. São muitos os discursos que nos chegam e são muitas as necessidades de lidar com eles no mundo do trabalho e fora do trabalho, não só para o desempenho profissional, como também para saber fazer escolhas éticas entre discursos em competição e saber lidar com as incertezas e diferenças características de nossas sociedades atuais (MOITA-LOPES; ROJO, 2004, p. 46). 
A ideia de uma pedagogia das múltiplas linguagens relaciona-se com o uso de modos de representação do significado que vão além do domínio da correspondência letra-som ou do foco em uma única linguagem, em que o ensino é visto como domínio de regras gramaticais para o "bem escrever" e o "bem falar" uma língua.

A pedagogia fundamentada nas múltiplas linguagens utiliza-se de uma variedade de linguagens e de modos de significação, uma variedade de recursos de ensino para diferentes fins culturais, fins de ensino e de avaliação. Os textos escrito, auditivo, espacial, gestual, em língua de sinais, corporais, em desenhos ou gravuras, em ambientes digitais, etc., fundamentam a pedagogia das múltiplas linguagens.

Assim, dois argumentos principais surgem: o primeiro é que a expressão múltiplas linguagens está relacionada não apenas às formas oficiais de letramento, utilizadas nas escolas, mas também às formas não incentivadas, desprezadas e marginalizadas. Dessa forma, as múltiplas linguagens focalizam tanto a realidade local quanto a conexão com o global, abrangendo tanto as variedades e situações diversificadas de linguagem quanto as diferenças culturais e corporais. $\mathrm{O}$ segundo argumento é bastante simples e decorre do primeiro: o seu significado está em diversas manifestações de linguagem.

Torna-se mister considerar a distinção entre letramentos dominantes e letramentos locais. Os dominantes ou também chamados de institucionalizados se associam às organizações formais, tais como a escola, o local de trabalho, a igreja, as burocracias. Neste campo, ocorre a ação de professores, especialistas, pastores e advogados. Esses agentes são valorizados à proporção "do poder de sua instituição de origem" (HAMILTON, 2002, p. 180). Já os letramentos locais ou também chamados de vernaculares não são regulados nem sistematizados por instituições. Desse modo, são desvalorizados e desprezados por serem práticas da vida cotidiana (HAMILTON, 2002).

Trabalhar com leitura e escrita na escola:

[...] é muito mais que trabalhar com a alfabetização ou alfabetismos, é trabalhar com os letramentos múltiplos, com as leituras múltiplas - a leitura na vida e a leitura na escola. Trata-se, então, de garantir que o ensino desenvolva as diferentes formas de uso das linguagens (verbal, corporal, plástica, musical, gráfica etc.) e das línguas (falar em diversas variedades e línguas, ouvir, ler e escrever). Para participar de tais práticas com proficiência e consciência cidadã, é preciso também que o aluno desenvolva certas competências básicas para o trato com as línguas, as linguagens, as mídias e as múltiplas práticas letradas, de maneira crítica, ética, democrática e protagonista (ROJO, 2009, p. 118). 
Dessa forma, as múltiplas linguagens ampliam a noção de letramento para além da escrita alfabética, extrapolando para o campo da imagem, da música e de outras semioses.

A Figura 1 apresenta os componentes das múltiplas linguagens.

Figura 1 - Múltiplas linguagens

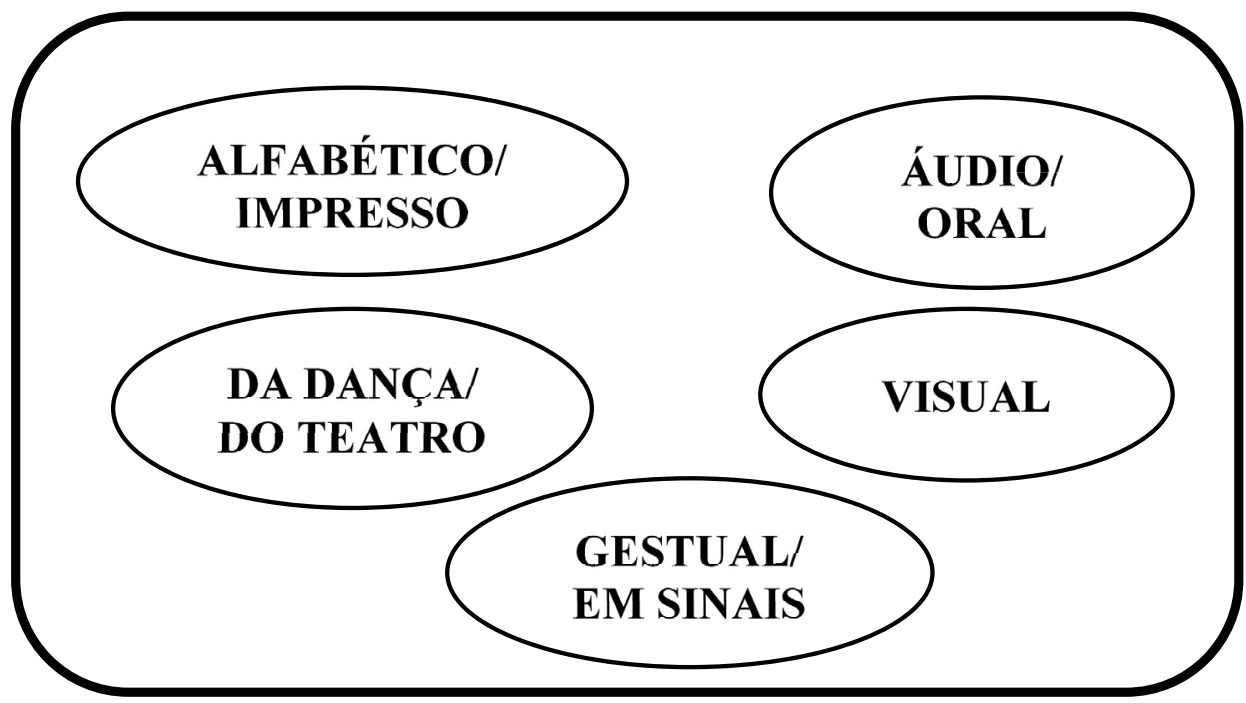

Fonte: elaboração dos autores, 2018.

De acordo com a Figura 1, percebemos que a alfabetização está inserida na linguagem alfabética/do texto impresso. Uma das metodologias de ensino que se utiliza na alfabetização inicia com o aprendizado das letras, passa-se para a junção em sílabas e a formação de palavras, para a chegada nas frases e nos textos escritos. Outra metodologia é a que parte do aprendizado dos gêneros textuais que circulam em sociedade, para aprender os textos de situações concretas, relacionando esses textos aos seus contextos e sentidos.

Acrescentam-se a essa metodologia algumas outras críticas ao ensino da escrita: a insistência de que o ideal da escola é ensinar a modalidade escrita; geralmente, as construções e as hipóteses dos alunos são ignoradas; a prioridade está na memorização de regras ortográficas; as atividades mais desenvolvidas são em torno de listas de palavras soltas ou de frases descontextualizadas; os textos produzidos serão lidos apenas pelo professor da turma; os textos são improvisados, sem planejamento e sem revisão. 
É visível que esta não é a única modalidade de letramento. A Figura 1 sugere outras múltiplas linguagens: áudio/oral, dança/teatro, visual, gestual/em sinais. $\mathrm{O}$ fato que justifica a abordagem de múltiplas linguagens para pessoas com deficiência é que a comunicação humana ocorre de diferentes maneiras. As possibilidades são variadas no que diz respeito tanto à expressão quanto à compreensão, perpassando as formas institucionalizadas das modalidades oral e escrita, uma vez que há possibilidades de expressão e compreensão por gestos, por sinais, por desenhos, por gravuras, pela dança, pelo teatro, pelo uso do computador e por outras ferramentas tecnológicas.

Quanto à linguagem áudio/oral, consideramos que "[...] há uma imbricação constitutiva entre fala/oralidade e escrita/letramento, mesmo quando se pensa que estamos 'apenas falando"' (BENTES, 2010, p. 138). Isso acarreta uma mudança nas análises de língua falada e escrita ou, como mencionamos, fala/oralidade e escrita/letramento.

Há, ainda, que se considerar que a política predominante no Brasil, no que se refere ao ensino e à propagação das línguas, é a do monolinguismo. Essa política impede o ensino de línguas consideradas minoritárias nas escolas, como é o caso das línguas faladas por cerca de 170 grupos indígenas - principalmente os que estão localizados na Região Amazônica -, bem como o caso das comunidades de imigrantes espalhadas por várias regiões do país, com a diversidade linguística de desprestigiados dialetos, que já convivem em contextos bidialetais, mas são impedidos de receber instrução em suas línguas.

Além do preconceito linguístico, há o caso de pessoas com deficiência, que encontram limites para pronunciar as palavras ou emitir certos fonemas, provocando dificuldade no entendimento: somente uma convivência prolongada reverte, em parte, essa situação. Há, ainda, uma multiplicidade de manifestações da oralidade proibidas na sala de aula, como certas músicas da periferia, as gírias e o vocabulário considerado pornográfico.

Quanto à linguagem da dança/do teatro, pontuamos que, com ela, alcança-se uma leitura múltipla de eventos sociais. Um dos objetivos dessas práticas de letramento é desenvolver a linguagem, a comunicação criativa, a potencialidade do uso do corpo como elemento artístico. A dança e o teatro são vistos como fatores relevantes no desenvolvimento pessoal e interpessoal, por isso as escolas, enquanto instituições que primam por esse desenvolvimento, devem perceber a dança e o teatro como elementos que precisam estar presentes no currículo escolar, enquanto práticas pedagógicas de crescimento individual e social. A dança e o teatro são fa- 
tores essenciais ao desenvolvimento corporal, à reflexão e à dinamicidade, fazendo com que os alunos envolvidos com estas linguagens melhorem significativamente a capacidade de interpretar o mundo e a realidade à sua volta, bem como possibilitam ver o mundo por uma outra perspectiva.

Quanto à linguagem visual, consideramos que a imagem ocupa grande espaço na vida das pessoas, estando presente em jornais, revistas, outdoors, sites da internet e também no corpo das pessoas que fazem tatuagens. Desse modo, as imagens constituem-se em uma forma de linguagem, o que permite uma multiplicidade de interpretações, no entanto, a utilização da imagem ainda está fora do ambiente escolar: os jogos eletrônicos são proibidos, a publicidade é pouco explorada e as revistas em quadrinhos são pouco utilizadas na sala de aula.

A partir dos anos de 1970, tem-se a utilização de imagens como forma de interação de pessoas com deficiência, uma vez que estas não possuem fala ou escrita funcional e não assimilam o sistema alfabético de escrita, em consequência de impedimentos de natureza física, mental, intelectual ou sensorial. Essa utilização de imagens recebeu a denominação de "comunicação alternativa", caracterizando a utilização, sobretudo, de pranchas ou cartelas com símbolos pictográficos para a expressão e recepção com outras pessoas, podendo ser usado o computador para a produção desses símbolos.

Outros instrumentos que precisam ser utilizados são os sites e jogos de computador para proporcionar aprendizagens, uma vez que envolvem não apenas a comunicação visual, mas também as linguagens auditiva, alfabética e imagética, em um espaço cibernético de intercomunicação.

Quanto à linguagem gestual/em sinais, ${ }^{2}$ ela foi recentemente incorporada nos discursos educacionais como mecanismo interativo de ativação de conceitos e de expressão. Os gestos podem ser independentes, bem como podem reforçar ou contradizer o sentido dado a um discurso oral. São expressões dos olhos, das mãos, da cabeça, dos braços, do corpo e do modo de andar, que conduzem significados em composição ou não com a palavra falada. Além disso, a utilização da língua de sinais pela comunidade surda e ouvinte ${ }^{3}$ sugere que o uso do aparelho fonador pode ser substituído por outros meios de produção de línguas. Nesse caso, o que substitui o aparelho fonador é, principalmente, os braços e as mãos. Esta linguagem estabelece certas configurações de mãos, articuladas em certos pontos do corpo ou fora dele, que, com possíveis movimentos e expressões faciais/corporais, compõem uma forma de comunicação sinalizada ou discursos realizados no espaço próximo ao corpo de um sinalizador. 
Por conseguinte, os meios utilizados para a produção de sinais constituem artefatos culturais e possuem gramática e estatuto de língua. Torna-se relevante frisar que a língua de sinais foi institucionalizada, no Brasil, com a aprovação da

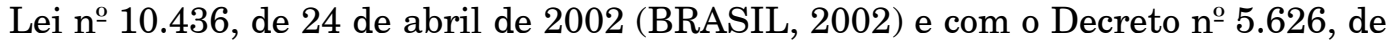
22 de dezembro de 2005 (BRASIL, 2005).

Reiteramos que este estudo teve como foco os resultados do uso de uma proposta de avaliação das capacidades e das potencialidades de pessoas com deficiência no âmbito escolar. As deficiências em questão foram: paralisia cerebral (PC); múltipla deficiência sensorial-visual (MDVI); deficiência intelectual (DI) - síndrome de Down; e surdez (S). Assim, façamos uma breve descrição destas deficiências.

A paralisia cerebral é:

[...] um grupo heterogêneo de transtornos motores não-progressivos causados por lesões cerebrais crônicas, que se originam no período pré-natal, período perinatal ou primeiros cinco anos de vida. Os quatro subtipos principais são espástico, atetóide, atáxico e paralisia cerebral mista, sendo a forma espástica a mais comum. O transtorno motor pode variar desde dificuldades no controle motor fino à espasticidade severa em todos os membros. A diplegia espástica (doença de Little) é o subtipo mais comum, e é caracterizado por espasticidade mais proeminente nas pernas que nos braços. Esta afecção pode estar associada com Leucomalácia periventricular (BADAWI et al., 1998, p. 520, tradução nossa).

A American Association on Intellectual and Developmental Disabilities (2018, p. 1, grifo do autor, tradução nossa) conceitua que:

[...] a deficiência intelectual é uma deficiência caracterizada por limitações significativas tanto no funcionamento intelectual quanto no comportamento adaptativo, que abrange muitas habilidades diárias sociais e práticas. Esta deficiência se origina antes da idade de 18 anos. $\mathrm{O}$ funcionamento intelectual - também chamado de inteligência - refere-se à capacidade mental geral, como aprender, raciocinar, resolver problemas, e assim por diante. Um critério para medir o funcionamento intelectual é o teste de quociente de inteligência (QI). As pontuações de QI entre 70 e 75 indicam uma limitação no funcionamento intelectual.

Em relação à múltipla deficiência sensorial-visual (MDVI),

[...] a pessoa com múltipla deficiência sensorial-visual (MDVI denominação internacional) é aquela pessoa que tem a deficiência visual (baixa visão ou cegueira) associada a uma ou mais deficiências (intelectual, física/ motora) ou a Distúrbios Globais do Desenvolvimento e Comunicação (MAIA; GIACOMINI; ARÁOZ, 2008, p. 51).

Em relação à surdez, o Decreto $\mathrm{n}^{\circ} 5.626 / 2005$ considera a pessoa surda aquela que, por ter perda auditiva, compreende e interage com o mundo por meio de experiências visuais, manifestando sua cultura principalmente pelo uso da Libras. No mesmo decreto, encontramos a definição de deficiência auditiva como a perda da audição de forma bilateral, parcial ou total. 
No tópico a seguir, apresentamos a estratégia metodológica deste estudo, com uma proposta de avaliação que proporcione aos professores uma análise que constate a situação de aprendizagem atual de pessoas com deficiência na escola. A partir desta apreciação, a ideia é criar atividades de linguagens, de modo que estas pessoas se apropriem de conhecimentos, conforme suas capacidades e potencialidades.

\section{Estratégia metodológica}

O presente estudo foi realizado por meio de uma pesquisa com características transdisciplinares, uma vez que tratou, segundo Rojo (2006, p. 258), “de problemas com relevância social por exigirem respostas teóricas que tragam ganhos a práticas sociais e a seus participantes, no sentido de uma melhor qualidade de vida, num sentido ecológico".

A pesquisa deu-se por meio de observações na Sala de Recursos Multifuncionais (SRM) de uma escola municipal em Belém, Pará, que foram realizadas no segundo semestre do ano de 2017. Durante os momentos de observação das pessoas com deficiência na escola e na sala de recursos, destacamos os seguintes fatores observados: uso da fala; uso da visão; uso da audição; uso do tato; uso da escrita; habilidade de movimentos; e habilidade cognitiva.

Com as observações, tivemos o propósito de apreender o cotidiano e a prática educativa dos professores que atuam com pessoas com deficiência na escola. $\mathrm{O}$ momento de observação nos proporcionou perceber como os professores aplicavam determinadas atividades com estas pessoas, assim como verificar de que forma encontram-se as instalações da SRM em que as pessoas com deficiência estudavam.

No momento das observações, utilizamos o diário de campo como instrumento para registrar os dados observados. O diário de campo, segundo Minayo (2015), é um caderno em que se registram as informações mais relevantes, tais como: as conversas, os relatos, as atitudes de professores e alunos, assim como os detalhes de cada atividade pedagógica desenvolvida no espaço investigado.

A escola pesquisada funciona em três turnos, manhã, tarde e noite, destinados à educação de jovens e adultos (EJA), e disponibiliza espaços diversos de aprendizagem, tais como: laboratório de informática, biblioteca, sala de leitura, aulas de artes, educação física e uma SRM. Em relação à SRM, tem-se como objetivo oferecer apoio pedagógico aos alunos deficientes, por meio de avaliação e fornecimento de recursos tecnológicos aos alunos, em horário contrário ao que estudam na escola. 
A sala de recursos pesquisada funciona nos turnos manhã e tarde, com dois professores que utilizam diversas linguagens - artística, tecnológica, corporal, literária, cênica, para atender cerca de trinta alunos de quatro outras escolas próximas do mesmo distrito administrativo. ${ }^{4}$

Os participantes desta pesquisa assinaram um termo de consentimento livre e esclarecido (TCLE), garantindo que suas identidades não sejam reveladas e que as informações prestadas sejam utilizadas unicamente para fins de divulgação científica. Tais informações respondem as questões éticas de pesquisas e são a garantia de que estas não trazem nenhum risco aos participantes, apenas benefícios, uma vez que, com os resultados desta pesquisa, outros pesquisadores e/ou professores poderão criar, a partir das sugestões propostas, melhores formas de verificação das capacidades e potencialidades de pessoas com deficiência.

Partimos, então, para a apresentação dos participantes da pesquisa. Destacamos que as denominações dos participantes são fictícias, a fim de preservar a verdadeira identidade de cada um, conforme informado no TCLE.

O participante com paralisia cerebral (PC), denominado Léo:

Tem 19 anos. Está no CIII-7º ano do ensino fundamental. É usuário de cadeira de rodas. Não consegue ficar em pé devido as suas condições físicas decorrentes da paralisia cerebral. As atividades de vida diárias não são possíveis de serem feitas sem a ajuda do acompanhante, o seu pai, que é uma pessoa idosa (Diário de campo realizado em 08/03/2017).

O participante com múltipla deficiência sensorial-visual (MDVI), denominado Alex:

Possui 20 anos. Está no CI $3^{\circ}$ ano do ensino fundamental. Não sai de casa sozinho, sempre tem a companhia dos responsáveis. Tem baixa visão, enxerga com a fonte 38 e tem miopia. Tem fala desenvolvida. Compreende o interlocutor. Escreve lentamente. Não consegue reter com propriedade os conteúdos e algumas letras. Já repetiu o CI três vezes (Diário de campo realizado em $21 / 03 / 2017$ ).

A participante com deficiência intelectual (DI) - síndrome de Down, denominada Ana:

Tem 10 anos. Está no CI $2^{\circ}$ ano do ensino fundamental. Apresenta síndrome de Down. É extrovertida. Muito agitada. Oraliza poucas palavras. Não escreve alfabeticamente. Consegue identificar figuras. Usa o apontar. Identifica partes do corpo (Diário de campo realizado em 22/03/2017).

A participante com $\operatorname{surdez}^{5}(\mathrm{~S})$, denominada Lia: 
Tem 18 anos. É de classe social baixa. Mora com a mãe e mais dois irmãos em um bairro da periferia de Belém. Estuda desde os sete anos de idade. Estudou em diversas escolas de Belém, repetindo em diversos anos. Está atualmente no CIII - $6^{\circ}$ ano do ensino fundamental. É uma pessoa surda. (Diário de campo realizado em 18/10/2017). ${ }^{6}$

É papel da escola e do professor a formulação de uma epistemologia-metodológica que atenda a todos os alunos, sobretudo as pessoas com deficiência, permitindo o acesso aos conhecimentos, a participação e a interação em sala de aula, partindo de suas diferentes subjetividades e características.

A seguir, com base nas constatações realizadas, passa-se a uma proposta de avaliação-intervenção, considerando as linguagens anteriormente discutidas, e apresentam-se os resultados da referida proposta de avaliação que considera as capacidades e potencialidades de pessoas com deficiência na escola.

\section{Resultados e discussão}

A proposta a ser desenvolvida não pretende ser mais um instrumento normalizador, no sentido de estabelecer comparações entre uma pessoa que tenha dicção, audição e escrita ideais e uma pessoa com deficiência na escola. Se fosse essa a intenção, o tipo de avaliação seria para medir a quantidade de acertos e erros a partir de questões ou informações solicitadas. Não temos essa intenção, pois entendemos que a aura da escola deve ser outra. Para Kenski (2000, p. 123):

A aura da escola depende de seus espaços e de seus atores. Professores e alunos parecem circular com suas presenças, mesmo nas suas ausências. O espaço da escola é mágico. Nele se realiza o milagre permanente do aprender e do abrir-se para o mundo. Múltiplas e diferenciadas são as linguagens da escola. Formas possíveis de, inclusive, recuperar, em nossas histórias, as imagens e os movimentos que constituíram os nossos aprendizados.

Pretendemos fazer constatações, que são discursos flexíveis, que buscam a cientificidade, uma vez que se baseiam em evidências e fatos concretos e comprovados e não no senso comum e na criação de afirmações generalistas. Algumas informações obtidas com os familiares podem refletir generalizações ou comparações com outras pessoas, neste caso cabe ao professor discutir formas de romper com essas representações normalizadoras e avançar em novas concepções: as concepções disnormalizadoras.

A concepção disnormalizadora, em termos gerais, é um discurso que se confronta com o anterior - a concepção normalizadora que concebe os sujeitos com 
uma padronização, com um corpo ideal -, estabelecendo uma disputa de posições e um desafio: o de lidar com a diferença constitutiva de cada ser humano.

A base de uma nova pedagogia fundada nas múltiplas linguagens implica uma avaliação do aluno que não apenas constate características de ausências, mas que, sobretudo, apresente possibilidades de o aluno interagir na escola e avançar em termos de conhecimentos.

Esclarecemos que as informações dispostas no Quadro 1, a seguir, são decorrentes de constatações que os pesquisadores obtiveram na observação quando do atendimento educacional especializado (AEE) realizado na escola municipal pesquisada. As transposições dessas constatações são decorrentes da observação e, também, de diagnoses de exames clínicos complementares - laudos das deficiências - vistos nos arquivos da sala de recursos.

Quadro 1 - Constatações dos quatro participantes da pesquisa

\begin{tabular}{|c|c|c|c|c|}
\hline Aspectos & Leo (PC) & Alex (MDVI) & Ana (DI) & Lia (S) \\
\hline Fala & $\begin{array}{l}\text { Oraliza poucas pa- } \\
\text { lavras, de forma in- } \\
\text { compreensível para o } \\
\text { interlocutor. }\end{array}$ & $\begin{array}{l}\text { Não tem problemas } \\
\text { de oralização. }\end{array}$ & $\begin{array}{l}\text { Oraliza poucas pala- } \\
\text { vras, de forma incom- } \\
\text { preensível para o inter- } \\
\text { locutor. }\end{array}$ & $\begin{array}{l}\text { Utiliza a Libras. } \\
\text { Oraliza de forma incom- } \\
\text { preensível para o inter- } \\
\text { locutor. }\end{array}$ \\
\hline Visão & $\begin{array}{l}\text { Não tem problemas } \\
\text { relacionados à visão. }\end{array}$ & $\begin{array}{l}\text { Apresenta proble- } \\
\text { mas relacionados à } \\
\text { visão. }\end{array}$ & $\begin{array}{l}\text { Não tem problemas re- } \\
\text { lacionados à visão. }\end{array}$ & $\begin{array}{l}\text { Não tem problemas re- } \\
\text { lacionados à visão. }\end{array}$ \\
\hline Audição & $\begin{array}{l}\text { Não tem limitações } \\
\text { auditivas. }\end{array}$ & $\begin{array}{l}\text { Não tem limitações } \\
\text { auditivas. }\end{array}$ & $\begin{array}{l}\text { Não tem limitações au- } \\
\text { ditivas. }\end{array}$ & $\begin{array}{l}\text { É surda profunda } \\
\text { (conforme laudo médi- } \\
\text { co). }\end{array}$ \\
\hline Tato & $\begin{array}{l}\text { Apresenta problemas } \\
\text { de coordenação mo- } \\
\text { tora. }\end{array}$ & $\begin{array}{l}\text { Apresenta proble- } \\
\text { mas de coordenação } \\
\text { motora. }\end{array}$ & $\begin{array}{l}\text { Usa o apontar. Identifica } \\
\text { partes do corpo. }\end{array}$ & $\begin{array}{l}\text { Tem coordenação mo- } \\
\text { tora fina com a mão es- } \\
\text { querda. }\end{array}$ \\
\hline Escrita & $\begin{array}{l}\text { Não consegue es- } \\
\text { crever com firmeza e } \\
\text { autonomia, devido as } \\
\text { suas condições físicas } \\
\text { decorrentes da parali- } \\
\text { sia cerebral. }\end{array}$ & $\begin{array}{l}\text { Não consegue es- } \\
\text { crever com firmeza e } \\
\text { autonomia. Escreve } \\
\text { lentamente. Conhe- } \\
\text { ce as letras: A, B, C, } \\
\text { D, I, J, M, O, T, U, X. }\end{array}$ & $\begin{array}{l}\text { Não escreve alfabetica- } \\
\text { mente. Consegue iden- } \\
\text { tificar figuras. Em ativi- } \\
\text { dade de escrita e leitura, } \\
\text { apresenta pouca concen- } \\
\text { tração. }\end{array}$ & $\begin{array}{l}\text { Copia com pouca auto- } \\
\text { nomia. Fica muito pró- } \\
\text { xima do papel, fica cur- } \\
\text { vada sobre a mesa para } \\
\text { escrever. Somente co- } \\
\text { pia os assuntos do qua- } \\
\text { dro ou de outras fontes. }\end{array}$ \\
\hline Movimento & $\begin{array}{l}\text { Não consegue se mo- } \\
\text { vimentar sozinho. Uti- } \\
\text { liza cadeira de rodas. }\end{array}$ & $\begin{array}{l}\text { Movimenta o lado } \\
\text { esquerdo. Não movi- } \\
\text { menta a sua cadeira } \\
\text { de rodas com auto- } \\
\text { nomia. }\end{array}$ & $\begin{array}{l}\text { Não tem dificuldade de } \\
\text { andar. Gosta de correr. } \\
\text { Corre pela escola. }\end{array}$ & $\begin{array}{l}\text { Não apresenta movimen- } \\
\text { tos involuntários. }\end{array}$ \\
\hline Cognição & $\begin{array}{l}\text { Não parece ter com- } \\
\text { prometimento cogni- } \\
\text { tivo. }\end{array}$ & $\begin{array}{l}\text { Não parece ter com- } \\
\text { prometimento cogni- } \\
\text { tivo. }\end{array}$ & $\begin{array}{l}\text { Apresenta pouca con- } \\
\text { centração nas ativida- } \\
\text { des. }\end{array}$ & $\begin{array}{l}\text { Não parece ter compro- } \\
\text { metimento cognitivo. }\end{array}$ \\
\hline
\end{tabular}

Fonte: elaboração dos autores, 2018. 
O objetivo do Quadro 1 é estabelecer uma avaliação diagnóstica para orientar a ação dos pesquisadores em diversas modalidades de linguagens. Como se observa, alguns aspectos indicam as capacidades e potencialidades atuais das pessoas com deficiência, ou seja, seus pontos fortes. A partir desses aspectos, devem ser implementados os planejamentos de ensino individualizados e coletivos, para favorecer um aprendizado significativo a estas pessoas na escola. Destacamos que os planejamentos coletivos devem se dar em função de elas estarem inseridas em sala de aula, junto com outros alunos da escola.

O Quadro 2 resume as sugestões de ações de múltiplas linguagens que o professor pode realizar para desenvolver as capacidades e potencialidades nos estudantes.

Quadro 2 - Possibilidades de linguagens dos quatro participantes da pesquisa

\begin{tabular}{|c|c|c|c|c|}
\hline Aspectos & Leo (PC) & Alex (MDVI) & Ana (DI) & Lia (S) \\
\hline $\begin{array}{l}\text { Alfabético/ } \\
\text { impresso }\end{array}$ & $\begin{array}{l}\text { Escreve com letras bas- } \\
\text { tão. }\end{array}$ & $\begin{array}{l}\text { Não é funcional, nem a } \\
\text { expressão nem a recep- } \\
\text { ção. }\end{array}$ & $\begin{array}{l}\text { Não é funcional, nem } \\
\text { a expressão nem a } \\
\text { recepção. }\end{array}$ & $\begin{array}{l}\text { Compara a Libras } \\
\text { com a língua portu- } \\
\text { guesa. }\end{array}$ \\
\hline Áudio/oral & $\begin{array}{l}\text { Embora apresente di- } \\
\text { ficuldade de ser com- } \\
\text { preendido, a expressão } \\
\text { ocorre pela oralidade. }\end{array}$ & $\begin{array}{l}\text { A expressão ocorre pela } \\
\text { oralidade. Sua fala é in- } \\
\text { teligível. }\end{array}$ & $\begin{array}{l}\text { A expressão ocorre } \\
\text { pela oralidade. Sua } \\
\text { fala é inteligível. }\end{array}$ & $\begin{array}{l}\text { A audição e a ora- } \\
\text { lização, em decor- } \\
\text { rência da surdez, } \\
\text { não são funcionais. }\end{array}$ \\
\hline $\begin{array}{l}\text { Da dança/ } \\
\text { do teatro }\end{array}$ & $\begin{array}{l}\text { Ainda não experimen- } \\
\text { tou possibilidades de } \\
\text { expressão pela dança e } \\
\text { pelo teatro. }\end{array}$ & $\begin{array}{l}\text { A expressão e a recepção } \\
\text { ocorrem pelos gestos, } \\
\text { podendo adaptar formas } \\
\text { de dança e teatro utilizan- } \\
\text { do a cadeira de rodas. }\end{array}$ & $\begin{array}{l}\text { Trabalha com ativida- } \\
\text { des de tempo curto, } \\
\text { que sejam envolven- } \\
\text { tes, adaptando formas } \\
\text { de dança e de teatro. }\end{array}$ & $\begin{array}{l}\text { A recepção é bem } \\
\text { compreendida quan- } \\
\text { do ocorre dramatiza- } \\
\text { ção. }\end{array}$ \\
\hline Visual & $\begin{array}{l}\text { Uso de pranchas co- } \\
\text { municativas ou fixação } \\
\text { do papel na mesa, para } \\
\text { evitar que se movimente } \\
\text { (carteira adaptada). }\end{array}$ & $\begin{array}{l}\text { Uso de pranchas comu- } \\
\text { nicativas ampliadas (fon- } \\
\text { te } 38 \text { ). }\end{array}$ & $\begin{array}{l}\text { Uso de pranchas co- } \\
\text { municativas. } \\
\text { Conversa por meio } \\
\text { de instruções e do } \\
\text { uso de gravuras. }\end{array}$ & $\begin{array}{l}\text { Uso da Libras e uso } \\
\text { de imagens. }\end{array}$ \\
\hline $\begin{array}{l}\text { Gestual/ } \\
\text { em sinais }\end{array}$ & $\begin{array}{l}\text { Não faz gestos com a } \\
\text { mão. Utiliza-se de ex- } \\
\text { pressões faciais. }\end{array}$ & $\begin{array}{l}\text { A expressão ocorre pe- } \\
\text { las expressões faciais/ } \\
\text { corporais e pelos gestos } \\
\text { de cabeça e de mãos. }\end{array}$ & $\begin{array}{l}\text { A expressão ocorre } \\
\text { pelo apontamento e } \\
\text { por gestos corporais. }\end{array}$ & $\begin{array}{l}\text { A expressão é pela } \\
\text { Libras. }\end{array}$ \\
\hline
\end{tabular}

Fonte: elaboração dos autores, 2018.

Com base nos elementos dispostos no Quadro 2, pontuamos que "[...] todas as pessoas se comunicam, ainda que em diferentes níveis de simbolização e com formas de comunicação diversas" (BOSCO; MESQUITA; MAIA, 2010, p. 11). Esse pressuposto nos direciona imediatamente para as múltiplas linguagens das pessoas com deficiência, considerando que, por mais acentuada que a deficiência possa 
ser, sempre há possibilidade de estabelecer uma interação: os comportamentos da pessoa estabelecem comunicação, seja receptiva ou expressiva.

A atuação do professor junto a pessoas com deficiência na escola implica a utilização de variadas formas de linguagens, o que recebe o nome de atividades pedagógicas de múltiplas linguagens, implicando o uso de textos com várias semioses e a utilização dos diversos sentidos e habilidades: o tato, a visão, a audição, a fala (oral ou em sinais), o movimento e a cognição.

De fato, "[...] um profundo conhecimento do aluno, do seu contexto familiar e social e das tarefas a serem realizadas na escola e fora dela possibilitará a tomada de decisões sobre qual recurso de comunicação será necessário para aquele aluno, naquele momento" (SARTORETTO; BERSCH, 2010, p. 50).

Os recursos de comunicação são variados, a depender das habilidades sensoriais que estão preservadas no sujeito. A função do professor de sala de aula comum é planejar o que vai ser feito em classe: estabelecer os objetos de ensino e utilizar instrumentos para ensinar esses objetos. Ao professor de sala de recursos, que atua no AEE, cabe o papel de construir recursos que favoreçam a participação das pessoas com deficiência em sala de aula comum, sugerindo um trabalho dinâmico com as múltiplas linguagens: alfabético/impresso; áudio/oral; da dança/do teatro; visual e gestual/em sinais.

Em relação aos aspectos alfabético e impresso:

Os avanços tecnológicos reorientam a leitura na escola para outros textos e imagens. $\mathrm{O}$ ato de ler se transforma historicamente. Não mais apenas a leitura obrigatória dos densos compêndios clássicos das ciências ou dos herméticos textos cheios de erudição, alguns incompreensíveis para os seus jovens leitores. Textos curtos, cartazes, intercalados com imagens, desenhos, filmes, literatura e conversas fazem a intermediação entre os textos clássicos e os hipertextos digitais. A escola precisa investir na formação de leitores por diversos caminhos e linguagens. Precisa também ampliar suas concepções de linguagem, de leitura e de escrita para incorporar as mediações textuais feitas a partir do uso das tecnologias digitais (KENSKI, 2000, p. 132-133).

Trazemos para o debate a relevância dos hipertextos digitais, pois são facilitadores da aprendizagem, capazes de promover oportunidades para o crescimento intelectual. Cabe à escola e ao professor ampliar suas concepções de leitura e de escrita, para incorporar outras atividades textuais feitas a partir do uso das tecnologias digitais. Assim, as pessoas com deficiência na escola terão a possibilidade de escolher diferentes direções a partir da dinamicidade de textos presentes em seu universo educacional.

Em relação aos aspectos áudio e oral: 
Existe nas escolas uma multiplicidade de vozes, de corpos e movimentos. Movimentos e corpos que se apresentam de forma diferenciada das posturas de professores e alunos. Sem precisar dizer, é possível saber pela "fala" do corpo a identidade de seu dono e a sua posição no contexto educativo: os que "ensinam" e os que "aprendem". Estes últimos, crianças e jovens em geral, possuem hábitos, atitudes e comportamentos que revelam uma nova cultura, em muitos casos ignorada (em alguns casos, rejeitada) pela escola (KENSKI, 2000, p. 126).

As pessoas com deficiência manifestam seus hábitos, atitudes e comportamentos por meio do movimento de seus corpos e das suas expressões faciais. Por isso, é imprescindível que a escola trabalhe, também, com a "fala" do corpo de seus alunos, em especial das pessoas com deficiência. Para as pessoas que conseguem realizar atividades relacionadas aos aspectos áudio/oral, torna-se relevante oportunizar o uso de estratégias e recursos de aprendizagem para o desenvolvimento das habilidades de compreensão e produção dessa linguagem.

Sobre os aspectos da dança e do teatro, Kenski (2000, p. 126) evidencia que “[...] os jovens manifestam suas diferenças nas roupas e nas formas como 'decoram' seus corpos: piercings e tatuagens, entre eles". Nesse sentido, a dança e o teatro, também, precisam acompanhar as especificidades dos jovens, pois são práticas educativas eficientes e que, por isso, devem estar presentes no processo educativo das pessoas com deficiência na escola.

A dança e o teatro oportunizam às pessoas com deficiência na escola a utilização de diferentes formas de linguagens presentes em nossa sociedade, tais como: a corporal, a visual, a verbal/sinalizada, a plástica, a escrita, entre outras. Isso contribui para o enriquecimento do aprendizado e possibilita o desenvolvimento da identidade e da autonomia das pessoas com deficiência. Por meio da dança e do teatro:

A linguagem dos corpos nas escolas, no entanto, se modifica a partir da proposta da música e da dança, linguagens não habituais no contexto escolar. Os corpos 'dóceis' se agitam e se movimentam em coreografias criativas. Dá-se o surgimento natural de lideranças, a 'performance' em equipes. Do movimento isolado e discreto de alguns ao livre envolvimento e fluidez grupal surgem novas formas de diálogo e ação escolar em que estão presentes a interação, a criatividade e o entusiasmo para o aprender. Momentos que originam, para os professores, oportunidades novas de estar com os alunos e de ouvir suas 'vozes'. Observar seus comportamentos. Descobrir aspectos capazes de estabelecer - em outros momentos criativos de ensino - as pontes e diálogos que garantam aproximação entre as culturas dos jovens e a da escola. Entre o conhecimento racional e contemplativo e a ação, a percepção e a emoção. Condições indispensáveis para se propor o ensinar para e em uma nova era (KENSKI, 2000, p. 127). 
É sob essa perspectiva que defendemos a presença da dança e do teatro na escola, ou seja, esta linguagem precisa ser trabalhada com o objetivo de proporcionar performances em equipes, movimentos grupais, diálogo e interação, bem como aproximação entre as culturas de pessoas com e sem deficiência. Somos a favor de uma dança e de um teatro que permitam o encontro com o outro ou outros e possibilitem a construção da identidade e da autonomia.

Sobre os aspectos visual e gestual/em sinais, Kenski (2000, p. 138) menciona que:

O ambiente da sala de aula, seus espaços e apetrechos também comunicam ações e intenções. Quando a aula termina, os alunos continuam próximos. Nos intervalos entre as aulas fortalecem-se as amizades, programam-se atividades sociais, desenvolvem-se afetos e cumplicidades. A coesão social - indispensável para a ação e formação do cidadão - nasce nas inter-relações pessoais que ocorrem nos intervalos, nos momentos de encontro presenciais e comunicativos fora das salas, mas dentro do espaço das escolas.

As pessoas com deficiência na escola e no ambiente da sala de aula comunicam ações e intenções, também, por meio de seus gestos, de seus sinais, de seus olhos e suas expressões faciais. É mister a escola e os professores utilizarem estratégias de ensino e recursos didático-pedagógicos que explorem os aspectos visual e gestual/ em sinais, sendo essencial para que a aprendizagem das pessoas com deficiência na escola ocorra de maneira positiva e a partir de suas experiências visuais.

Com base no que delineamos acerca dos aspectos alfabético/impresso, áudio/ oral, da dança/do teatro, visual e gestual/em sinais, destacamos a necessidade de a avaliação de pessoas com deficiência na escola considerar as múltiplas linguagens. Com isso, a escola e os professores estarão cumprindo funções pedagógicas, didáticas e diagnósticas, as quais recorrem a instrumentos de verificação do rendimento escolar de pessoas com deficiência.

Ao considerar as múltiplas linguagens, a avaliação refletirá de forma qualitativa no trabalho escolar, do aluno e do professor, proporcionando mudanças na vida escolar das pessoas com deficiência. Assim, torna-se relevante mencionarmos que, antes de a avaliação ser efetivada, é necessário que seja realizado o planejamento das atividades a serem desenvolvidas com as pessoas com deficiência na escola.

Então, quem planeja é o professor. Quem sugere formas de mudanças para que as pessoas com deficiência participem das atividades é o professor especializado da sala de recursos. Esse professor mobiliza meios e modos que favoreçam a participação das pessoas com deficiência nas atividades escolares. 
Há uma diferença entre a atuação do professor da sala comum e a do professor do AEE. Enquanto o primeiro ocupa-se do ensino dos conhecimentos acadêmicos, o segundo identifica as possíveis barreiras impostas pela deficiência e pelo meio e disponibiliza recursos e estratégias para que este aluno consiga participar, por meio da ampliação de sua comunicação e intervenção no meio, dos vários desafios à aprendizagem na escola (SARTORETTO; BERSCH, 2010, p. 55).

As orientações didáticas gerais podem ser resumidas nos seguintes itens:

a) descrever oralmente as imagens, os vídeos, os diagramas para pessoas com baixa visão, cegas e com dificuldades de compreensão de imagens;

b) traduzir o texto para Libras, quando alunos surdos estiverem participando das atividades;

c) proporcionar momentos de interação a partir da dramatização em sala de aula;

d) fornecer imagens e traduzir todo o texto para vídeos, que podem ser vistos por pessoas com deficiência intelectual;

e) gravar textos escritos em áudio, construindo audiolivros;

f) gravar falas que possam ser acionadas por pessoas sem oralidade, mas que escutam;

g) produzir imagens da comunicação alternativa;

h) promover o acesso à leitura e à produção de textos escritos ou visuais, utilizando o computador;

i) produzir animações e vídeos para a compreensão das informações;

j) fazer com que as pessoas com deficiência na escola contem e recontem narrativas de seu cotidiano;

k) incentivar a leitura e a escrita das pessoas com deficiência na escola a partir das narrativas de seu cotidiano;

1) realizar um trabalho com as pessoas com deficiência na escola a partir dos diversos gêneros textuais em sala de aula.

Essas orientações didáticas poderão proporcionar ao professor e às pessoas com deficiência na escola momentos avaliativos mais dinâmicos, a partir de variadas formas de linguagens ou atividades pedagógicas de múltiplas linguagens. Com isso, inferimos que a avaliação das pessoas com deficiência na escola assumirá um caráter de respeito às múltiplas linguagens destas pessoas. 
O trabalho que considere as múltiplas linguagens das pessoas com deficiência, além de elaborar ricos e diversificados ambientes com materiais diversos, proporciona possibilidades variadas de aprendizagens, por meio de: gesto, sinal, desenho, gravura, dança, teatro, uso do computador, cinema, dança, exposições, literatura, música, textos diversos, entre outras possibilidades. Com isso, as pessoas com deficiência na escola poderão ampliar o direito às manifestações artísticas e culturais para além do contexto escolar.

\section{Considerações finais}

O debate acerca das múltiplas linguagens é fundamental para enriquecer a discussão sobre a avaliação de pessoas com deficiência na escola. Isso porque se considera que a escola não é mero lugar de sociabilização dessas pessoas, mas o lugar em que vão desenvolver capacidades de expressão, de negociação, de críticas, de lutas e conquistas por melhores condições de vida acadêmica e profissional, o que pode ocorrer por meio de variadas formas de linguagem.

Se a pessoa com deficiência na escola não escreve, ela pode ser capaz de se expressar por meio de desenhos, Libras ou gravuras de uma comunicação alternativa, ou ainda por gestos ou por um sistema computacional que favoreça sua comunicação. Todas essas formas precisam ser reconhecidas pela sociedade e pelas instituições educativas como possibilidades de estabelecer interação, de construir sentidos nos seus textos conforme suas diferenças.

Tal ideia também se aproxima das discussões sobre as diferenças culturais ou a diversidade de identidades, ampliando a discussão em torno de gênero, etnia, orientação sexual para outros marcadores, como os da deficiência. Não se trata apenas de um pluralismo simplista e passageiro, que vê a diferença como exótica e imutável. A diferença passa a ser a questão principal a ser debatida, e as pessoas com deficiência assumem o centro, demonstrando que podem ser quebrados parâmetros comparativos com corpos ideais, com capacidades ideais e valorizadas.

Nesta visão, não deveria haver um padrão de pessoa, um ideal de língua, uma cultura ou identidade valorizada como universal. A pluralidade de discursos de oposição é mais produtiva. Conforme nossas constatações, a pedagogia que estamos nomeando como das múltiplas linguagens pode atender a diversas deficiências - como os sujeitos com paralisia cerebral, com múltiplas deficiências, com deficiência intelectual e com surdez -, o que pode ser um contraponto às ideologias sobre o corpo perfeito e os padrões de língua única centrada apenas em uma abordagem monolíngue. 
Com efeito, os quadros apresentados neste artigo são elementos discursivos e materiais importantíssimos, que revelam ao professor o modo como as pessoas com deficiência na escola se manifestam nas suas formas singulares de linguagem e os comportamentos modificados nesse processo de aprendizagem. Esses quadros de avaliação permitem, ainda, ao professor, por meio desses critérios de caráter disnormalizador, visualizar um perfil inicial de cada aluno. Além disso, as atividades propostas são refutadas ou aceitas, permitindo ao professor elencar um conjunto de atividades de natureza diversa, adaptável às condições de pessoas com deficiência, as quais são mais propícias ao processo de ensino e aprendizagem.

A avaliação de pessoas com deficiência na escola vem sendo encarada e percebida por muitos professores, em especial aqueles de turmas inclusivas, como um processo complexo, devido às particularidades e às necessidades de cada pessoa com deficiência, bem como ao seu desenvolvimento diferenciado, que, muitas vezes, é visto como um desenvolvimento que vai na contramão dos alunos que se destacam em sala de aula. Contudo, pensamos que os professores possuem um relevante papel a desempenhar no momento da avaliação de pessoas com deficiência na escola, pois o processo avaliativo dessas pessoas servirá para que os professores possam definir outras estratégias de ensino e outros recursos didáticos e pedagógicos que venham instigar as capacidades e potencialidades das pessoas com deficiência na escola.

\section{Nota}

1 Neste estudo, utilizamos o termo “pessoa(s) com deficiência”, conforme a Lei no 13.146/2015, que, em seu art. $2^{\circ}$, define que a pessoa com deficiência é aquela que tem impedimento de longo prazo de natureza física, mental, intelectual ou sensorial e que, em interação com uma ou mais barreiras, pode obstruir sua participação plena e efetiva na sociedade em igualdade de condições com as demais pessoas (BRASIL, 2015).

2 Em relação ao termo "linguagem gestual/em sinais", pontuamos que as línguas de sinais, incluindo a Língua Brasileira de Sinais (Libras), são definidas como línguas com estrutura gramatical própria, semelhantes às línguas orais, embora a comunicação, receptiva ou expressiva, dos seus usuários seja realizada por meio dos gestos e dos sinais (GESSER, 2009).

3 Destacamos que o uso da língua de sinais dá-se pela comunidade surda, por pessoas surdocegas, por instrutores de Libras e por grupos de ouvintes, como os intérpretes de Libras/Português, por professores bilíngues de ensino básico e superior e por familiares de surdos.

4 A cidade de Belém, no Pará, é dividida em distritos administrativos e não em zonas, como outras capitais brasileiras. No caso, a escola pesquisada faz parte do chamado Distrito Administrativo de Belém (DABEL), que abrange os bairros de Batista Campos, Campina, Cidade Velha, Fátima, Nazaré, Reduto, São Brás, Umarizal e Marco, conforme a Lei nº 7.682, de 05 de janeiro de 1994 (BELÉM, 1994).

5 Optamos em utilizar a denominação (participante "com surdez"), para que concorde com o elemento central deste estudo, que são as "pessoas com deficiência”, pois todos os participantes são definidos com uso da preposição "com" seguida da deficiência do referido participante. Pontuamos que há uma série de discussões em torno do termo "pessoa surda", inclusive o termo "Surdo(a)" ou "Surdos(as)", para alguns pes- 
quisadores, deve ser escrito com inicial maiúscula, pois marca uma concepção política de surdez, vista para além do fator biológico ou clínico-terapêutico (DORZIAT, 2009). Há discussões em torno da definição estabelecida pelo Decreto oㅜ 5.626/2005, que considera a pessoa surda aquela que interage no mundo por meio da Libras, e pessoa com deficiência auditiva (ou pessoa com surdez) aquela que tem perda da audição, mas que não interage no mundo por meio da Libras. Há pesquisadores que mencionam que o termo "pessoa com surdez", refere-se aos aspectos clínico-terapêuticos relacionados à perda auditiva e à deficiência (FERNANDES, 2011). Destacamos que a participante Lia é uma pessoa que utiliza a Libras para se comunicar na escola.

6 É importante destacar que, no município de Belém, o ensino fundamental é organizado em Ciclos I, II, III e IV. O Ciclo I tem duração de três anos, o que equivale às turmas de $1^{\circ}, 2^{\circ}$ e $3^{\circ}$ anos; Ciclo II $-4^{\circ}$ e $5^{\circ}$ anos; Ciclo III $-6^{\circ}$ e $7^{\circ}$ anos; e Ciclo IV $-8^{\circ}$ e $9^{\circ}$ anos.

\section{Referências}

AMERICAN ASSOCIATION ON INTELLECTUAL AND DEVELOPMENTAL DISABILITIES. Definition of Intellectual Disability. 2018. Disponível em: <http://aaidd.org/intellectual-disability/definition\#.Wq0M4KjwbIU>. Acesso em: 17 mar. 2018.

BADAWI, N. et al. What constitutes cerebral palsy? Developmental Medicine \& Child Neurology, Bruxelas, v. 40, n. 8, p. 520-527, Aug. 1998. Disponível em: <https://onlinelibrary.wiley.com/doi/ epdf/10.1111/j.1469-8749.1998.tb15410.x>. Acesso em: 17 mar. 2018.

BELÉM. Lei no 7.682, de 05 de janeiro de 1994. Dispõe sobre a regionalização administrativa do município de Belém, delimitando os respectivos espaços territoriais dos distritos administrativos e dá outras providências. Belém, 1994. Disponível em: <https://cm-belem.jusbrasil.com.br/legislacao/583592/lei-7682-94>. Acesso em: 24 mar. 2018.

BENTES, A. C. Linguagem oral no espaço escolar: rediscutindo o lugar das práticas e dos gêneros orais na escola. In: RANGEL, E. O.; ROJO, R. H. R. (Coord.). Língua Portuguesa: ensino fundamental. Brasília, DF: Ministério da Educação; Secretaria de Educação Básica, 2010. p. 129-154. Disponível em: <http://portal.mec.gov.br/index.php?option=com docman\&view=download\&alias=7840-2011-lingua-portuguesa-capa-pdf\&category_slug=abril2011-pdf\&Itemid=30192> . Acesso em: 17 mar. 2018.

BOSCO, I. C. M. G.; MESQUITA, S. R. S. H.; MAIA, S. R. A educação especial na perspectiva da inclusão escolar: surdocegueira e deficiência múltipla. Brasília, DF: Ministério da Educação; Secretaria de Educação Especial; Fortaleza: Universidade Federal do Ceará, 2010.

BRASIL. Lei no 10.436, de 24 de abril de 2002. Dispõe sobre a Língua Brasileira de Sinais - Libras e dá outras providências. Brasília, DF, 2002. Disponível em: <http://www.planalto.gov.br/ ccivil_03/Leis/2002/L10436.htm>. Acesso em: 17 mar. 2018.

. Decreto $\mathrm{n}^{\mathrm{0}} 5.626$, de 22 de dezembro de 2005. Regulamenta a Lei $\mathrm{n}^{\mathrm{o}} 10.436$, de 24 de abril de 2002 e o art. 18 da Lei no 10.098, de 19 de dezembro de 2000. Brasília, DF, 2005. Disponível em: <https://presrepublica.jusbrasil.com.br/legislacao/96150/decreto-5626-05>. Acesso em: 17 mar. 2018.

Lei no 13.146, de 6 de julho de 2015. Institui a Lei Brasileira de Inclusão da Pessoa com Deficiência (Estatuto da Pessoa com Deficiência). Brasília, DF, 2015. Disponível em: <http:// www.planalto.gov.br/ ccivil_03/_Ato2015-2018/2015/Lei/L13146.htm>. Acesso em: 17 mar. 2018. 
DORZIAT, A. O outro da educação: pensando a surdez com base nos temas identidade/diferença, currículo e inclusão. Petrópolis, RJ: Vozes, 2009.

FERNANDES, S. Educação de surdos. 2. ed. atual. Curitiba: Ibpex, 2011.

GESSER, A. Libras? Que língua é essa? Crenças e preconceitos em torno da língua de sinais e da realidade surda. São Paulo: Parábola, 2009.

HAMILTON, M. Sustainable literacies and the ecology of lifelong learning. In: HARRISON, R. R. F.; HANSON, A.; CLARKE, J. (Org.). Supporting lifelong learning. V. 1: Perspectives on learning. London: Routledge; Open University Press, 2002. p. 176-187.

KENSKI, V. M. Múltiplas linguagens na escola. In: CANDAU, V. M. (Org.). Linguagens, espaços e tempos no ensinar e aprender. Rio de Janeiro: DP\&A, 2000. p. 123-140.

LIBÂNEO, J. C. Didática. São Paulo: Cortez, 1994.

MAIA, S. R.; GIACOMINI, L.; ARÁOZ, S. M. M. Desenvolvimento da aprendizagem em crianças com deficiência múltipla sensorial. In: COSTA, M. P. R. (Org.). Múltipla deficiência: pesquisa \& intervenção. São Carlos, SP: Pedro \& João Editores, 2008. p. 49-64.

MELO, A. M.; PUPO, D. T. A educação especial na perspectiva da inclusão escolar: livro acessível e informática acessível. Brasília, DF: Ministério da Educação; Secretaria de Educação Especial, 2010 .

MINAYO, M. C. de S. Trabalho de campo: contexto de observação, interação e descoberta. In: p. 61-77.

(Org.). Pesquisa social: teoria, método e criatividade. 34. ed. Petrópolis: Vozes, 2015.

MOITA-LOPES, L. P.; ROJO, R. H. R. Linguagens, códigos e suas tecnologias. In: BRASIL. Ministério da Educação. Orientações Curriculares de Ensino Médio. Brasília, DF: MEC/SEB/ DPEM, 2004. p. 14-56.

QUADROS, R.; CRUZ, C. Línguas de sinais: instrumentos de avaliação. Porto Alegre: Artmed, 2011.

ROJO, R. H. R. Fazer linguística aplicada em perspectiva sócio-histórica: privação sofrida e leveza do pensamento. In: MOITA-LOPES, L. P. (Org.). Por uma linguística aplicada indisciplinar. São Paulo: Parábola, 2006. p. 253-276.

ROJO, R. Letramentos múltiplos, escola e inclusão social. São Paulo: Parábola, 2009.

ROPOLI, E. A. et al. A educação especial na perspectiva da inclusão escolar: a escola comum inclusiva. Brasília, DF: Ministério da Educação; Secretaria de Educação Especial, 2010.

SANT'ANNA, I. M. Por que avaliar? Como avaliar? Critérios e instrumentos. 3. ed. Petrópolis: Vozes, 1995.

SARTORETTO, M.; BERSCH, R. de C. R. A educação especial na perspectiva da inclusão escolar: recursos pedagógicos acessíveis e comunicação aumentativa e alternativa. Brasília, DF: Ministério da Educação; Secretaria de Educação Especial, 2010. 


\section{Reflexões sobre a relação de crianças surdas com um recurso digital para a apropriação de língua portuguesa escrita em ambiente escolar}

\section{Reflections on the relationship of deaf children with a digital resource for the appropriation of Portuguese written in a school environment}

Heloísa Andreia de Matos Lins*

Janaina Cabello*

\section{Resumo}

A partir de pesquisa anterior sobre a criação de um recurso digital para ensino-aprendizagem de língua portuguesa escrita como segunda língua (L2), o presente artigo busca evidenciar a importância de considerarmos as percepções das crianças (particularmente as surdas, neste caso) para a elaboração conjunta desses materiais. São apresentados alguns registros das interações, em sala de aula, de um grupo de crianças surdas - meninas entre 7 e 11 anos de idade - com o artefato digital desenvolvido, em que se destacam as formas de audiência infantil na relação com o docente surdo e a mídia em questão. Tendo como aportes teóricos a Pedagogia da Infância e os estudos no campo da Filosofia da Diferença, conclui-se que o espaço escolar tem se configurado como local em que tanto o desenvolvimento de recursos didáticos na educação bilíngue de crianças surdas como as práticas pedagógicas nesse sentido são ainda amplamente controlados pelos adultos. Nesse sentido, considera-se a necessidade de tensionar práticas tradicionais de ensino de língua portuguesa como $L 2$ para crianças surdas, uma vez que há possibilidades para fazeres pedagógicos menos normativos na educação bilíngue, a partir do envolvimento das crianças neste processo e de um outro olhar dos pesquisadores e produtores de recursos midiático-tecnológicos nesse ínterim.

Palavras-chave: Infância. Língua portuguesa como L2. Surdez. Tecnologias.

Recebido em 07/08/2018 - Aprovado em 31/01/2019

http://dx.doi.org/10.5335/rep.v26i2.8473

Doutora em Educação pela Faculdade de Educação da Universidade Estadual de Campinas. Professora do Programa de Pós-Graduação na Faculdade de Educação da Universidade Estadual de Campinas - Linhas Linguagem e Arte em Educação e Educação e Ciências Sociais, Brasil. E-mail: hmlins@unicamp.br

** Mestra e doutoranda em Educação pela Faculdade de Educação da Universidade Estadual de Campinas, na linha de pesquisa Linguagem e Arte em Educação. Professora do Departamento de Psicologia da Universidade Federal de São Carlos, Brasil. E-mail: janainacabello@ufscar.br 


\title{
Abstract
}

\begin{abstract}
Based on a previous research on the creation of a digital resource for teaching and learning Portuguese as L2, the present article seeks to highlight the importance of considering children's perceptions (particularly the deaf ones, in this case) for the joint elaboration of these materials. Some records of the classroom interactions of a group of deaf children - girls between 7 and 11 years of age - are presented with the digital artifact developed, highlighting the forms of children's agency in the relationship with the teacher deaf and the media in question. Having as theoretical contributions the Pedagogy of Childhood and studies in the field of Philosophy of Difference, it is concluded that the school space has been configured as a place where both the development of didactic resources in the bilingual education of deaf children, such as pedagogical practices in this sense, are still largely controlled by adults. In this sense, it is considered the need to stress traditional Portuguese language teaching practices as L2 for deaf children, since there are possibilities for less normative pedagogical activities in bilingual education, from the involvement of children in this process and from another researchers and producers of media-technological resources in the meantime.
\end{abstract}

Keywords: Childhood. Portuguese Language as L2. Deafness. Technologies.

\section{Um contexto sobre a criação de um recurso digital para ensino-aprendizagem de crianças surdas e a interlocução com os estudos da infância}

No ano de 2011, houve a criação do Grupo de Estudos Surdos e Novas Tecnologias (Gestec), ${ }^{1}$ vinculado ao grupo de pesquisa ALLE (Alfabetização, Leitura e Escrita), da Faculdade de Educação da Universidade Estadual de Campinas, em que os processos de alfabetização e letramento (também digitais) na surdez eram temas centrais na discussão de alguns pesquisadores, professores, estudantes de pós-graduação, graduação e outros interessados na temática. A partir disso, algumas pesquisas se voltaram para o desenvolvimento de atividades para um possível aprimoramento das práticas pedagógicas nas escolas de educação básica, tendo como cenário a perspectiva bilíngue na educação de surdos, que tem como pressuposto "[...] que o surdo [...] deve adquirir como língua materna a língua de sinais, considerada a língua natural dos surdos e, como segunda língua, a língua oficial de seu país" (GOLDFELD, 2001, p. 42).

Algumas dessas atividades desenvolvidas foram concebidas como artefatos digitais, ou seja, recursos criados com o objetivo de serem materiais didático-pedagógicos desenvolvidos em suportes digitais e que abarcam possibilidades de contemplar diferentes linguagens (ou semioses) em seu desenvolvimento, além da escrita, tais como imagens, vídeos, cores, áudio, por exemplo. Nas palavras de Rojo (2012, p. 19), recursos que "[...] impregnam e fazem significar os textos contemporâneos quase tanto ou mais que os escritos em letra". 
Portanto, através da utilização de recursos digitais e do uso das novas mídias e tecnologias disponíveis livremente, o Gestec procurava elaborar artefatos digitais para facilitar processos de alfabetização e letramento de crianças surdas, principalmente, e também ouvintes, em início do processo de escolarização, garantindo, para tal, “[...] a presença do 'tripé' Língua Portuguesa em sua modalidade escrita, Libras - a Língua Brasileira de Sinais - (sinais) e Imagem (referentes ao significado das palavras/sinais)" (LINS, CABELLO, 2013, p. 86-87), na tentativa de promover às crianças surdas o acesso à Libras e à língua portuguesa escrita, de modo que elas possam perceber a função social de cada uma, bem como suas diferenças.

A presença desta tríade de semioses (escrita - sinal em Libras - imagem) é condição primordial em uma educação fundamentada nos pressupostos do bilinguismo para os surdos, uma vez que,

[...] se a escrita não repete a história da fala [para crianças surdas] e se é necessário que a criança se desligue do aspecto sensorial dos sons da fala para a construção desse sistema, o aluno surdo terá na língua de sinais a grande possibilidade para desempenhar essa tarefa sem contar necessariamente com a intermediação da fala [oral] (GESUELI, 2003, p. 150).

Em se tratando das potencialidades trazidas pelas mídias digitais, principalmente recursos como imagens e vídeos, a língua de sinais pode ser aliada aos demais recursos semióticos que privilegiam as potencialidades visuais na produção de materiais bilíngues, como aponta Lebedeff (2014, p. 1074):

Para dar conta das especificidades da Libras, tais como os canais de produção e recepção serem diferentes dos das línguas orais e o respeito pela característica visual da língua de sinais, acredita-se que os vídeos são excelentes recursos didáticos, para serem utilizados tanto na modalidade presencial como na modalidade a distância. Entretanto, apenas vídeos de elementos lexicais, que reproduzem a experiência das antigas cartilhas impressas, as quais apresentavam o desenho do sinal com seu significado, não possibilitariam a imersão em práticas sociais de linguagem.

Atentando-nos a essa ressalva feita por Lebedeff, naquele período, observávamos a expressiva falta desses recursos digitais que, de fato, priorizassem a Libras e uma pedagogia bilíngue/bicultural e visual, que:

[...] deve basear-se numa ampla visão sócio-antropológica [sic] segundo a qual o surdo é um indivíduo com características diferentes da maioria, [...] e que, historicamente, como tantas outras minorias, tem sido impedido de exercer seus direitos sociais - principalmente o de usar uma língua diferente e de ser educado na sua língua natural (SÁ, 1997, p. 17). 